\title{
Urban Influence on Relative-Humidity and its Corresponding Effects on Rainfall, a Case Study of Ibadan, Nigeria
}

\author{
Babatola E. B. \\ Department of Geography \& Geo-science \\ Joseph Ayo Babalola University, Ikeji-Arakeji, Osun state, Nigeria. \\ e-mail ; waleexcellent@yahoo.com
}

Doi: 10.5901/mjss.2013.v4n4p343

\begin{abstract}
Urbanization is one serious process that transforms natural environment into various surfaces that have long run pronounced effects on the whole atmospheric system. For instance subjection of one time thick forest surface into concrete and asphalt surfaces greatly altered aerodynamic processes in the area, water balance system as well as evapo-transpiration process.As it is known that availability of moisture is one of the evidences of precipitation process. This paper explored urban effects on relative-humidity, through loss of moisture due to loss of water retention surfaces and as such intercepting water balance system which probably could influence rainfall occurrence in the area. The data for this paper are secondary data; in which mean monthly relative-humidity and mean monthly rainfall were collected across seven stations over the period of twenty years, (1989-2009). Data were analysed using Mean graph, Pearson correlation and Anova. The results showed that relativehumidity over time indicate increase in urban land surface transformation. Mean graph shows almost increase relative-humidity with time across the stations as well as rainfall, which indicate increase of relative-humidity with urbanization, as well as increase rainfall with increase relative-humidity. These validated both hypotheses. It is therefore concluded that urbanization increases relative-humidity and that relative-humidity has corresponding influence on rainfall.
\end{abstract}

Key words: Natural-environment, Urbanization, Surface-transformation, Evapo-transpiration, Precipitation.

\section{Introduction}

The physical processes affecting the local climate are determined by surface conditions, location and exposure of the area and surface conditions such as heat capacity, moisture content, vegetation cover, albedo and roughness of the ground surface. Local climate are defined as the climate in an area where the local conditions of the earth's surface are clearly different from those in nearby surrounding areas, for example, regarding hills, forest, city, crop lands, rivers, and mountain environment (Oliveira, A.P. 2003). It comprises a number of micro-climate within an area of distinctive surface features (Schneider, S.H. 1996).

A major cooling factor in a natural environment is the evapo-transpiration process, which occurs in areas with vegetation and access to water and acts cooling due to the energy consumed in the process .Reduction of natural vegetations in an area lessen the possibilities for the evapo-transpiration process and thereby possibly reduces the natural cooling effect in a city where vegetation is scarce (Stone et al. 2001). Due the pave ground urban areas have a much faster run-off of excessive water, which may further reduce the natural cooling due to the shorter time the water is available for evaporation.

The process of urbanization produces radical changes in the nature of the surface and atmospheric properties of a region. It involves the transformation of radiation, thermal, moisture, and aerodynamic characteristics and thereby dislocates the natural solar and hydrologic cascades. For instance, the seemingly inevitable increase of air pollution affects the transfer of radiation, and supplies extra nuclei around which cloud droplets may form. The water input to the system is greater because its precipitation is augmented by water released to the atmosphere by combustion and urban water supply piped in from rivers or reservoirs. On the other hand, it seems likely that evapo-transpiration and subsurface storage in urban condition are less than in the rural situation. Evapo-transpiration is expected to be reduced because of the removal of vegetation and its replacement by impervious materials. This paper in its stand to contribute to knowledge explains how the growth of urban area gradually changes climate overtime.

The study area for this paper is a reality of urbanization talking in term of transformation of urban land surfaces, the data collected over time also represent the transformation of urban land surface over time, which is the manifestation of 
increasing urbanization in the area over the period studied. As such, using the study area as a reference point this paper want to corroborate the fact that land surface transformation from natural to artificial surfaces dynamically affect evapotranspiration system which greatly determine occurrence of humidity and the latter in turn has effect on water balance system in which rainfall is directly affected. The objectives of this paper are to examine the urbanization (land surface transformation) on relative-humidity, as well as investigating possible effect of relative-humidity on rainfall.

The influence of urbanization on local and regional climate is demonstrated in a situation where the urban area is assumed to be $40 \%$ agricultural crops, $10 \%$ water bodies, $30 \%$ forest, and $20 \%$ built up areas; and is adjacent to the surrounding area which consists of : (a) bare, dry land and (b) land completely covered by unstressed vegetation. When the terrain is bare, dry soil, the flow at low level is out from the developed area, whereas air moves to the developed area if unstressed vegetation is on its periphery. These model results suggest that land use changes in their spatial distribution can cause alterations in local and regional climate (Oke, T.R.1987).

Jauregui E. et al. (1992) concludes that city acts as moisture source; increasing the relative-humidity of air which is likely cause for the cool island in the city, especially in the dry season. This effect is mainly noticed in hot, dry climates, with dry rural surroundings and several irrigated areas, such as parks within city. This allows a lager evapo-transpiration process consuming more energy to take place in the city compare to the rural surroundings, thus acting as a heat sink (Saaroni et al 2000).

The effect of an open water body (generating moisture content in the air as such increase the relative humidity of the air at a certain temperature) would act cooling on the air temperatures due to the energy absorbed in the process. However, water has a very high capacity to store heat (Oke, T.R. 1987) and can therefore absorb the heat source. In a study of the Mediterranean city of Tel Aviv, which has similar climate to the tropics during the warm, dry period of the year, by Saaroni et al.(2000). It is concluded that the impact of the sore station (still located within the city centre) during this period exceeds the urban effects and results in warmer temperature during day due to the moderating effects of the sea. In a study Tso (1996) it is declared that Singapore benefits from the direct oceanic effect which improves the thermal conditions. The same results also concluded in a study of the Persian Gulf by Bitan \&Saaroni (1992).

Moisture overriding associated with fronts in an overall major method of precipitation production. If enough moisture and upward motion is present, precipitation falls from convective clouds such as cumulonimbus and organize into narrow rain bands where relatively warm water bodies are present, for example due to water evaporation from lakes; lake effect snow falls becomes a concern down-wind from lake within the cold cyclonic flow around the back side of extra tropical cyclonic. Lake-effect snow fall can be locally heavy. Thunder snow is possible within a cyclone's comma head and within lake effect precipitation bands. In mountainous areas, heavy precipitation is possible where upslope flow is maximized with windward sides of the terrain at elevation. On the leeward side of mountains, desert climate can exist due to dry air caused by compression heating. The urban heat island effects characteristic of the city leads to increase rainfall, both in amount and intensity, downward of cities. The urban islands warm cities $0.6^{0}\left(1.1^{0} \mathrm{~F}\right)$ to $5.6^{0}\left(10.1^{10} \mathrm{~F}\right)$ above surrounding suburbs and rural areas. This is extra thunder storm activity .Rainfall rate down- wind cities increased between $48 \%$ and $116 \%$. Partly as a result of this warming, monthly rainfall is about $28 \%$ greater between 20 miles (32 $\mathrm{km})$ to 40 mile $(64 \mathrm{~km})$ down-wind of cities, compared with upward. Some cities induce a total precipitation increase of $51 \%$.

\section{Significant of the Study}

One of the major effects of climate change experience today is the change in the nature of occurrence of climatic elements such as temperature, rainfall, relative-humidity, pressure, etc. As a result of environmental transformation from various human activities like; industries, constructions, buildings, etc. Basically, wanton clearance of vegetative covers for road construction, industrial development and rapid increase of buildings in the surfaces are all the processes of urbanization which eventually culminate in reduction of evapo-transpiration and so lead to low moisture contents in the atmosphere and therefore has great influence on water balance system in such an area, creating seemingly low rainfall in an area. This paper thus examined urban surfaces as they intercept water balance system in the study area through their influence on water vapour contents in the atmosphere and how this probably affect rainfall of the study area.

\section{Hypotheses}

i. Hi- That urbanization (Land surface transformation) influences relative-humidity in the study area.

ii. $\quad \mathrm{Hi}$ - That influences of urbanization (Land surface transformation) on relative-humidity has a corresponding effect on rainfall increase in the study area. 


\section{Study Area}

Location

The study area for this paper is Ibadan. The city of Ibadan is located on Latitude 7020' and 7026'of the equator and on Longitude 3048'and 3056' East of the Green-which meridian. Ibadan is directly connected to many towns as its rural hinterland by a system of roads, railways and air routes.

\section{Growth and Urban Land Use}

Ibadan has grown so rapidly that within a period of only 150 years, it has become one of the greatest metropolitan areas in Africa. Ibadan remains a major commercial, educational and administrative centre in Nigeria today and is improving its industrial base in the recent years. As noted by Mabogunje (1968). "It was the pinnacle of pre-European urbanism in Nigeria and the largest purely African city and the emporium for commerce of an extensive region". Of course, since the country became independent Ibadan had utilized not only the initial advantage acquired as headquarter of the old western region but also harnessed its location advantage to continue the domination of commerce in the old western Nigeria. Thus, in spite of the decentralization of civil service employment following the creation of states in 1976 and 1991, Ibadan remains a major commercial, educational and administrative centre and recent years has embarked upon improving its industrial base.

In its stride to becoming one of the Africa's greatest cities, Ibadan metropolis area has also shared in many of the problems that attend such ambitions, environmental pollution and environmental deterioration are as endemic in Ibadan as they are in Lagos (Ayeni B.O. 1981). Nonetheless, the Municipal planning Authority is one of the best staffed in the country such that given the means and the where withal, it should be able to successfully plan to solve many of these problems.

\section{The Ibadan City Climate and Its Variation}

Ibadan enjoys the characteristics West African Monsoonal climate, marked by distinct seasonal shift in wind pattern just because of its latitudinal location (lat. 07020' and 07026' North) and (3048'and 3056'). Between March and October, the city is under the influence of the moist maritime south-west monsoon winds which below inland from the Atlantic Ocean. This is rainy season. The dry season occurs from November to February when the dry dust-laden winds blow from the sahara desert.

On a micro scale, spatial variations occur across the city according to the density of urban structure. Ibadan climate exhibit its distinct characteristics through differences, between the city-centre and the surrounding country side, in such climatic parameters as temperature, humidity, wind, atmospheric content, and possibly rainfall. While such variations in climatic parameters have been adequately documented in respect of many cities in temperate latitude, a search through the literature reveals that similar studies on tropical cities are very few. Map of urban surface of Ibadan is shown below. 
Fig 1; Map showing the urban land-use of Ibadan

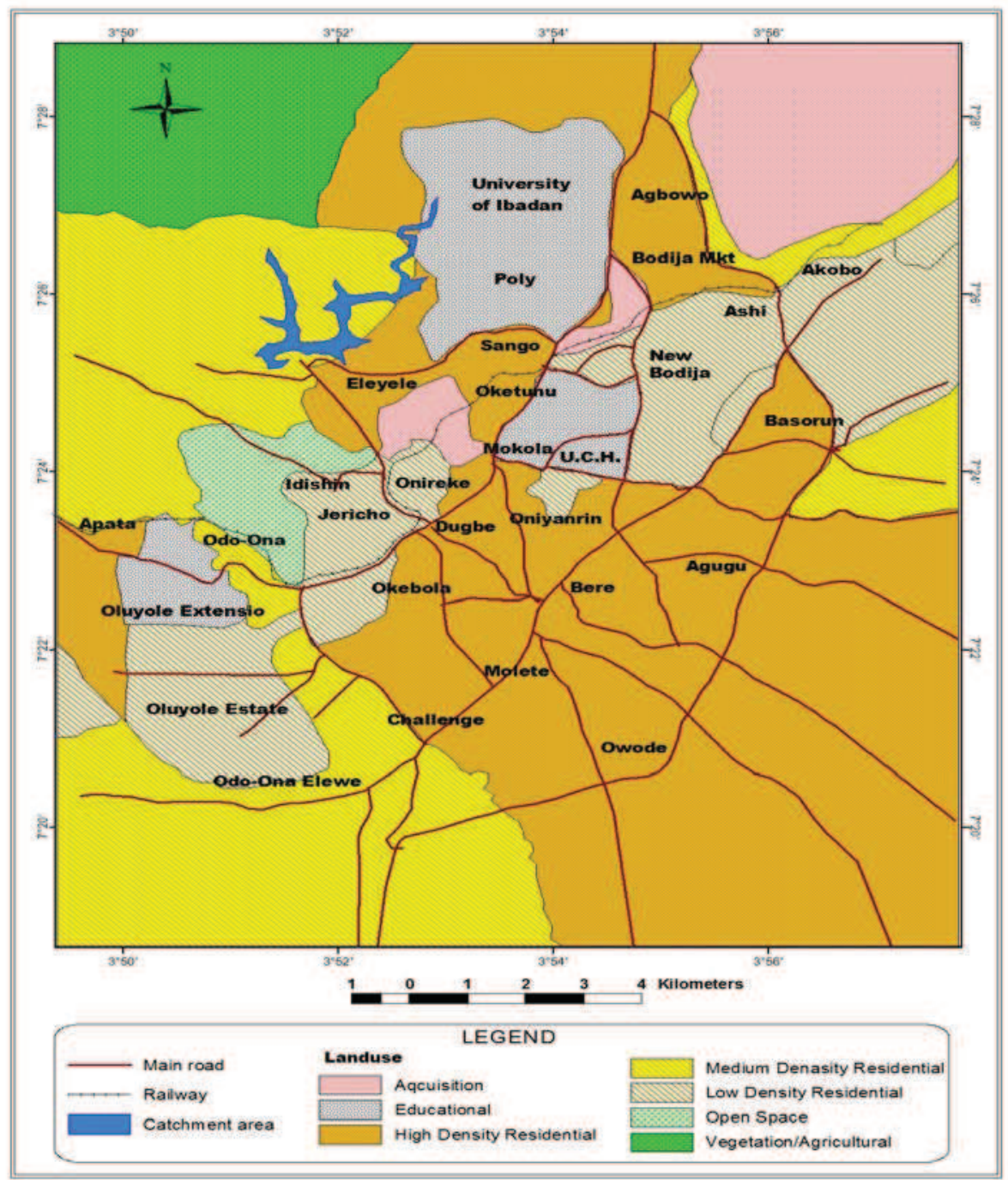

Source: Adapted from Ayeni 1994

\section{Methodology}

Data collection; The data for this paper were collected through secondary sources; that is, mean monthly relativehumidity and mean monthly rainfall over seven stations where weather elements are routinely measured and recorded. Data were collected for the period of twenty years; 1989-2009 in the study area. These stations are: Cocoa Research Institute of Nigeria (CRIN), Nigeria Institute of Horticulture (NIHORT), Institute of Intra-Tropical Agriculture (IITA), NewAirport, Institute of Agriculture research \& Training (IAR\&T), Forest Institute of Nigeria (FRIN), National Cereals Research Institute (NCRI). The map of these stations in the study area was shown in Fig 2. Although the stations of the data collection do not cover the whole of Ibadan, the areas still correctly relevant in terms of urban surface which is the basis of this research, and the interpretation will be limited to these areas. 
Fig 2;Map showing the stations of climatic data

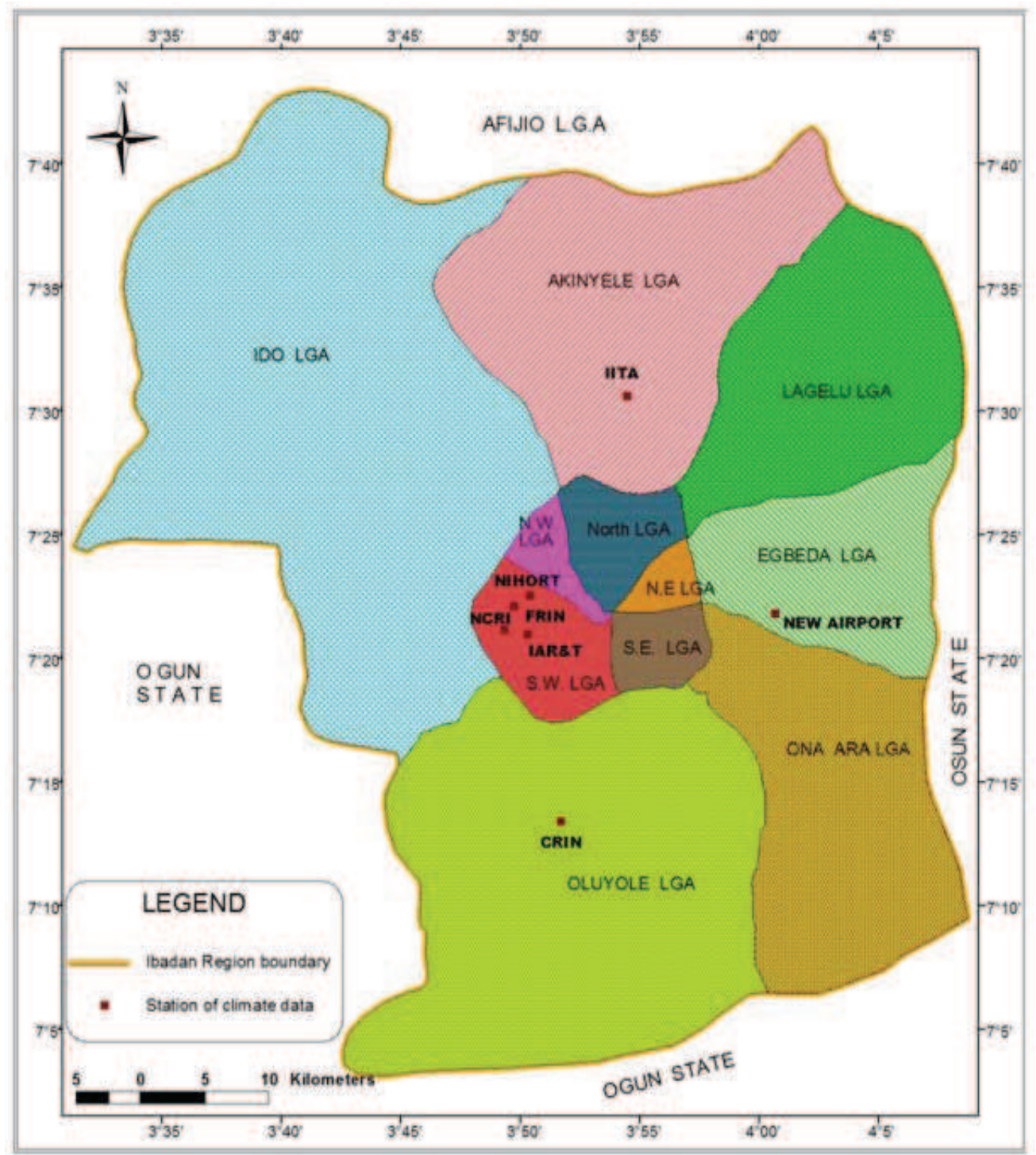

Source: From author's field work , 2010.

\section{Data Analyses}

The data in this paper is analysed using descriptive and inferential statistics. In descriptive statistics; mean graphs were used to illustrate; the trends of relative-humidity across the stations over time (the time lags represent increase in urbanization), as well as comparing relative-humidity with rainfall in order to explain the similarity and differences in the pattern of both of them. In inferential statistics; ANOVA, and Correlation Coefficient are used to analyse both Increase in Urbanization effect (i.e. increase in urban land surface transformation) on relative humidity as well as relationship between relative humidity and rainfall. 


\section{Results of Data Analyses}

\subsection{Descriptive Statistics}
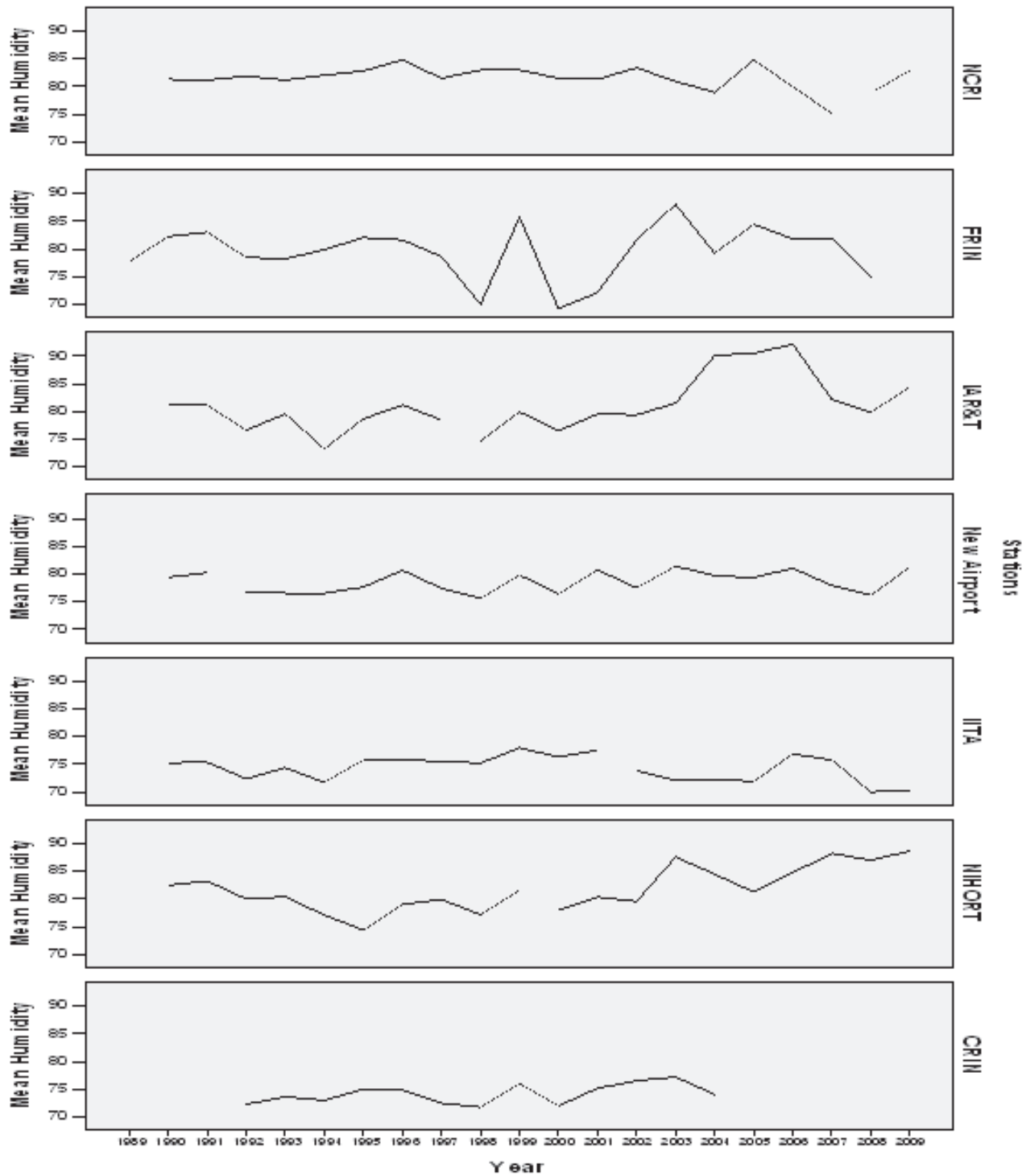

Fig. 3: Mean Humidity graph across seven stations over twenty years in the study area 


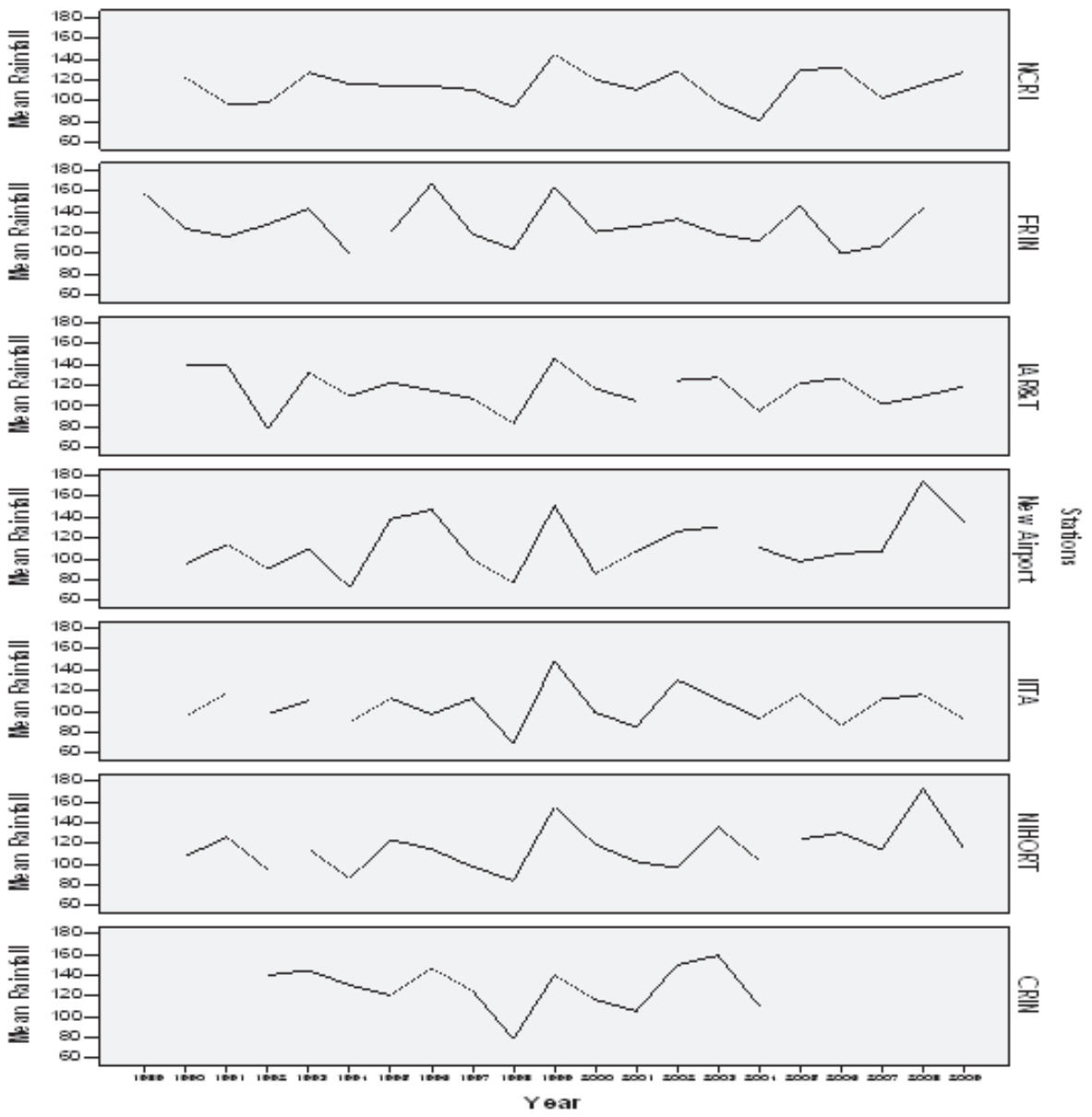

Fig. 4: Mean Rainfall graph across seven stations over twenty years in the study area

6.2 Inferential Statistics

\subsection{Correlation Analysis}

Correlations

\begin{tabular}{|l|l|c|c|c|c|}
\hline & & $\begin{array}{c}\text { Org } \\
\text { Stations }\end{array}$ & $\begin{array}{c}\text { Temp } \\
\text { Temperature }\end{array}$ & $\begin{array}{c}\text { Rfall } \\
\text { Rainfall }\end{array}$ & $\begin{array}{c}\text { Hmdty } \\
\text { Humidity }\end{array}$ \\
\hline \multirow{4}{*}{ Org Stations } & $\begin{array}{l}\text { Pearson } \\
\text { Correlation }\end{array}$ & 1 & .034 & .004 & $.157\left({ }^{* *}\right)$ \\
\cline { 2 - 6 } & Sig. (2-tailed) & & .200 & .862 & .000 \\
\cline { 2 - 6 } & $\mathbf{N}$ & 1596 & 1452 & 1525 & 1552 \\
\hline \multirow{3}{*}{$\begin{array}{l}\text { Temp } \\
\text { Temperature }\end{array}$} & $\begin{array}{l}\text { Pearson } \\
\text { Correlation }\end{array}$ & .034 & 1 & $-.108\left(^{* *}\right)$ & $\left.-.093{ }^{(* *}\right)$ \\
\cline { 2 - 7 } & Sig. (2-tailed) & .200 & & .000 & .000 \\
\hline & $\mathbf{N}$ & 1452 & 1452 & 1381 & 1440 \\
\hline
\end{tabular}




\begin{tabular}{|c|c|c|c|c|c|}
\hline \multirow{3}{*}{ Rfall Rainfall } & $\begin{array}{l}\text { Pearson } \\
\text { Correlation }\end{array}$ & .004 & $-.108\left({ }^{* *}\right)$ & 1 & $.522\left({ }^{* \star}\right)$ \\
\hline & Sig. (2-tailed) & .862 & .000 & & .000 \\
\hline & N & 1525 & 1381 & 1525 & 1482 \\
\hline \multirow{3}{*}{ Hmdty Humidity } & $\begin{array}{l}\text { Pearson } \\
\text { Correlation }\end{array}$ & $.157\left(^{* \star}\right)$ & $\left.-.0933^{* *}\right)$ & $\left..522{ }^{(*}\right)$ & 1 \\
\hline & Sig. (2-tailed) & .000 & .000 & .000 & \\
\hline & $\mathrm{N}$ & 1552 & 1440 & 1482 & 1552 \\
\hline
\end{tabular}

Anova Analysis

ANOVA

Hmdty Humidity

\begin{tabular}{|l|r|l|l|l|l|}
\hline & Sum of Squares & Df & Mean Square & F & Sig. \\
\hline Between Groups & 13731.018 & 6 & 2288.503 & 26.736 & .000 \\
\hline Within Groups & 132244.915 & 1545 & 85.595 & & \\
\hline Total & 145975.934 & 1551 & & & \\
\hline
\end{tabular}

Anova Analysis

ANOVA
Rfall Rainfall
\begin{tabular}{|l|r|r|r|r|r|r|}
\hline & Sum of Squares & df & Mean Square & F & Sig. \\
\hline Between Groups & 75166.249 & 6 & 12527.708 & 1.422 & .202 \\
\hline Within Groups & 13371964.006 & 1518 & 8808.935 & & \\
\hline Total & 13447130.255 & 1524 & & & \\
\hline
\end{tabular}

\section{Discussion of Results}

\subsection{Descriptive}

Hi: That urbanization increases relative humidity

Considering the graphs in Fig3 above, they show general increase across the stations around the periods 2003 to 2007, and tend to fall down towards the later end of the period that is, 2008 and 2009. The above observation means that urban heat island effect made evapo-transpiration higher across almost all the stations between 2003 and 2007 possibly because; i. urban areas generate heat, ii. Increase heat leads to increase loss of evapo-transpiration to the atmosphere. iii. There were still more moisture retaining surfaces like forest surfaces or better say natural surfaces. The graph showing fall in trend toward 2008 \&2009 may be most likely because of a drastic reduction in moisture retaining surfaces across the area which caused reduction in loss of evapo-transpiration and led to possibly reduction of relative-humidity, this is a picture of urban area. One could conclude that $\mathrm{Hi}$ : That urbanization increases relative-humidity in the study area is accepted.

Hi: That relative-humidity has corresponding influence on rainfall increase

Considering the Mean graph of rainfall in Fig 4 and compare it with Mean graph of relative-humidity in Fig 3, it could be observed that the two graphs almost follow the same pattern which could make one to conclude that relative humidity 
most likely influence rainfall in the study areas; it can be explained further that amount of relative-humidity in the atmosphere determines the amount of rainfall. This therefore validated the Hi: That relative-humidity have corresponding influence on rainfall.

\subsection{Inferential}

Correlation analysis was used to analyse, the significance of relative-humidity across the stations and also correlation between the relative-humidity and rainfall was also analysed. Anova was also used to test the significance of relative humidity across the stations in the study area, as well as the significance of the corresponding influence of relative humidity on rainfall.

Considering the correlation analysis table, relative-humidity has the value 0.000 for sig (2-tailed), which implies that relative humidity is significant in the study areas, since the value is not above 1 . Also relative-humidity has a value of 0.157 for pearson correlation under organization (stations) which means that there is a positive correlation between the stations and the relative-humidity over time that is, as the land surfaces are changing due to urbanization over time relative-humidity is increasing even though the relationship between them is $25: 4$ that is, as change of 25 in one brings change of 4 in other, which could be interpreted as increase of 25 in urbanization brings increase of 4 in relative-humidity.

The Hi: That urbanization increases relative-humidity is valid in the study area

Considering the Anova Analysis table, the value of $F$ is 26.379 while significance value is 0.000 it means that relative-humidity is significant across the area, since the significant value $<$ F- value, as such urbanization increases relative-humidity. The Hi: That urbanization increases relative-humidity is significant in this study area.

$\mathrm{Hi}$ : That relative-humidity has corresponding influence on rainfall increase

\section{Correlation Analysis}

Considering the correlation Analysis table above the value of rainfall is 0.000 for sig(2-tailed). This implies that rainfall is significant in the study area, since the value is not above 1. Looking at the Pearson correlation value of rainfall with relative-humidity it is 0.522 which means that there is positive correlation between rainfall and relative-humidity in the study area that is, increase in relative-humidity brings the corresponding increase in rainfall. The relationship between the two is 2: 1, increase of 2 in one brings increase of 1 in other which could be interpreted as increase of 2 in relativehumidity brings increase of 1 in rainfall. It is therefore concluded that $\mathrm{Hi}$ : That relative-humidity has corresponding influence on rainfall is valid in the study area.

Looking at the Anova Rainfall table, F value is 1.422 and significant value is 0.202 , this indicates that rainfall is significant in the staudy area, having said that, compare the Anova humidity table, the $F$ value is 26.736 and the significant value is 0.000 means that relative-humidity is significant in the study area. This is to say that both relativehumidity and rainfall are significant in the study area and so it means that significance of one is a corresponding significance of other. It is therefore concluded that $\mathrm{Hi}$ : That relative-humidity has corresponding influence on rainfall increase is valid for the study area.

\section{Conclusion and Recommendation}

\section{Conclusion}

This paper after carried out its research in the study area, came to the view that the rate of urbanization is high in the study area over the time studied, and that there is significant influence of urbanization on relative-humidity. It was also the opinion of this study that relative-humidity really have close association with rainfall, as such there is much influence of relative-humidity on rainfall.

\section{Recommendation}

Although the rate of urbanization in the study area was guessed base on the analyses of the data over time usually 20 years, this not to say that this study really delved into reality of urbanization in the area, so this study recommended that in the future study, the rate of urbanization base on actual land transformation should be studied to arrive at more valid result. 


\section{References}

Ayeni, B.(1981); 'Lagos' in M. Pacione ed. Problem and Planning in third World Cities. Croom Helm London. Pp 127-155

Babatola E.B. et al (2011); Alteration of Natural Environment; A result of change in Urban Temperature, TJOTBE, Joseph Ayo Babalola University, lkeji-Arakeji, vol1 ,N01:66-77.

Jauregui E. et al (1992); Aspects heat-island development in Guadalajara, Mexico. Atmospheric Environment 26B:391-396.

Oguntoyinbo , J. S. (1978): Aspect of Urban Micro climate: The case of Ibadan , in Sada P.O. and Oguntoyinbo J.S. (eds.) Urbanization Process and Problem in Nigeria, Ibadan University Press.

Oke T.R(1987); Boundary Layer Climate 2nd Edition, University Press, Cambridge, 435p

Oke T. R. et al (1991): "Simulation of surface Urban Heat Island under ideal condition at Night part 2: Diagnosis of causation", Boundary Layer Meteorology 56 339-358.

Oliver J.E. (ed) (2005); Encyclopaedia of World Climatology, Springer, Berlin p854.

Oliveira A.P. et al.(2003); Annual and diurnal wind pattern in the city of Sao Paolo. Water Air and Soil Pollution: Focus 3:3-15

Saaroni et al (2000); Spatial distribution and micro scale characteristics of urban heat island In Tel AVIV, Isreal, Land Scape and Urban Planning 48,1-18

Schneider S. H. (ed), (1996); Encyclopaedia of Weather and Climate, Oxford University Press New York, p.929.

Stone et al. (2001); Urban Form and Thermal Efficiency: How the Design of Cities Influence The Urban Heat Island Effect, Journal of the American Plans Ass.

Tso C.P. (1996); A survey of urban heat island studies in two tropical cities. Atmospheric Environment 30: 507-519 